\title{
Conjugal Transfer of Immunity to Phage $\lambda$ Multiplication in Escherichia coli $\mathrm{K}-12$
}

\author{
BY K. W. FISHER \\ Medical Research Council, Microbial Genetics Research Unit, \\ Hammersmith Hospital, Ducane Road, London, W. 12
}

\section{SUMMARY}

The transfer of a cytoplasmic component from $\lambda$-lysogenic $\mathrm{F}^{+}$to non-lysogenic F $^{-}$cells of Escherichia coli $\mathrm{K}-12$ was demonstrated; similar transfer from $\lambda$-lysogenic $\mathbf{H f r}$ to non-lysogenic $\mathbf{F}^{-}$cells was not detected. The component transferred confers on the recipient cell temporary immunity against maturation of the bacteriophage $\lambda$. The relevance of these observations to the mechanism of conjugation is discussed.

\section{INTRODUCTION}

The demonstration of zygotic induction (Jacob \& Wollman, 1954) and studies on non-inducible mutants of bacteriophage $\lambda$ (Jacob \& Campbell, 1959) have led to the idea of the existence of a specific cytoplasmic repressor, capable of maintaining either prophage or superinfecting phage $\lambda$ in a non-vegetative condition. Work by Bertani (1956) and Bertani \& Six (1958) suggested in the case of prophage P2, that immunity of lysogenic bacteria was probably due to a physiologically active prophage product, i.e. a repressor. The demonstration of the transfer of this repressor would substantiate its existence and reveal the occurrence of cytoplasmic transfer in some of the conjugal systems of Escherichia coli $\mathrm{K}-12$. There have been previous reports from work with $\mathrm{Hfr} \times \mathrm{F}-$ crosses, based on the inability to detect the transfer of phage genomes and of the enzyme $\beta$-galactosidase, that cytoplasmic transfer does not occur (Jacob \& Campbell, 1959; Pardee, Jacob \& Monod, 1959). The results of experiments reported here support this conclusion but demonstrate the occurrence of cytoplasmic transfer in $\mathrm{F}^{+} \times \mathrm{F}^{-}$crosses, the term cytoplasmic being used to denote anything of a non-chromosomal location.

\section{METHODS}

Media. Nutrient broth was prepared from Oxoid no. 2 powder at $25 \mathrm{~g} . / 1$. and adjusted to $\mathrm{pH} \mathbf{7 \cdot 4}$.

Nutrient agar was prepared by solidifying nutrient broth with agar powder (Davis Gelatine (N.Z.) Ltd., Christchurch, New Zealand) at 12 g./l.; ' $\lambda$ agar' was prepared by solidifying nutrient broth with agar powder at $8 \mathrm{~g} . / 1$.; 'top agar' was prepared by solidifying nutrient broth with agar powder at $5 \mathrm{~g}$./l.

Minimal agar was described by Tatum \& Lederberg (1947) except that asparagine was omitted and the medium solidified with agar powder at $15 \mathrm{~g} . / \mathrm{l}$.

Organisms. All of the strains used in this work were derivatives of Escherichia coli K-12. Characteristics of the strains used, and the order in which the initial markers of the various Hfr strains are transferred, are shown in Table 1. 
Wild-type $\lambda$ phage suspensions were prepared by ultraviolet (u.v.) induction of Escherichia coli K-12 strain Y 10. The final titre was about $2 \times 10^{10}$ plaque-forming particles (p.f.p.)/ml. Coliphage T6 was prepared by infection of $E$. coli B. Suspensions of this phage, containing about $5 \times 10^{10}$ p.f.p. $/ \mathrm{ml}$. were employed in some experiments to kill the donor strains.

Table 1. Sirains of Escherichia coli $K-12$ used

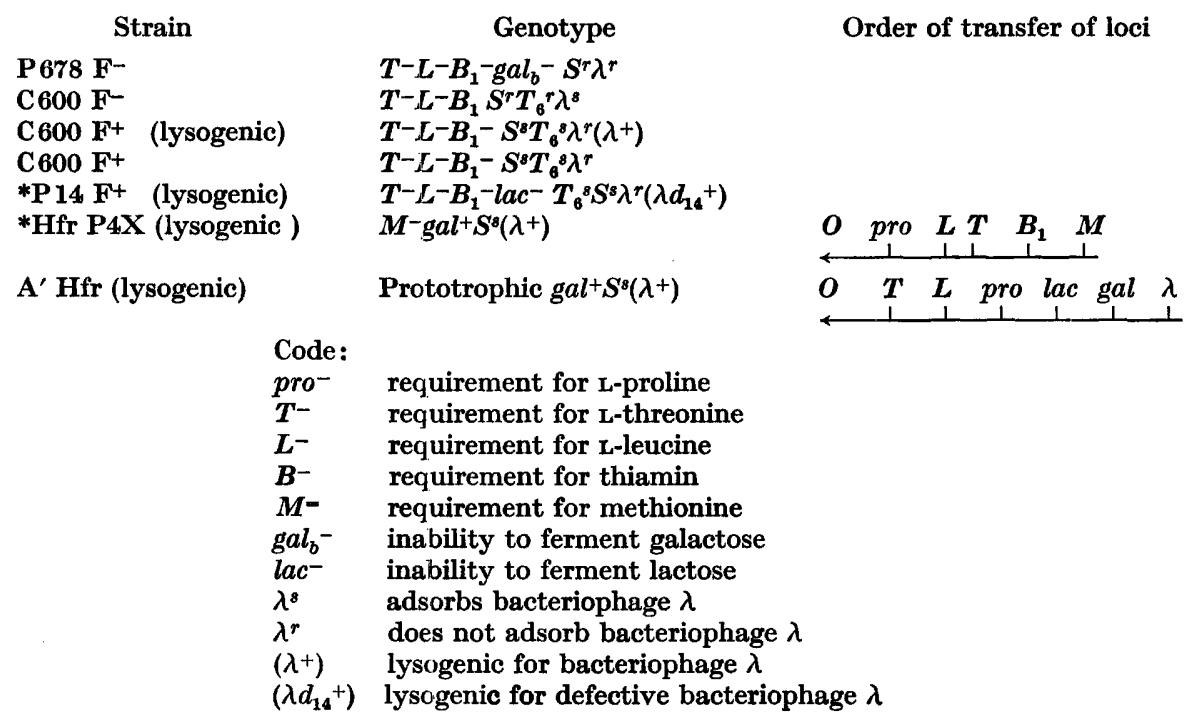

$\mathrm{S}^{8}$ or $\mathrm{S}^{\mathrm{r}}$ sensitivity or resistance to $200 \mu \mathrm{g}$. streptomycin $/ \mathrm{ml}$. respectively.

$T_{6}{ }^{r}$ or $T_{6}{ }^{8}$ resistance or sensitivity to coliphage $T 6$ respectively.

* Strains kindly provided by Dr IF. Jacob.

Assays. The following technique was used throughout these experiments for the detection and assay of $\lambda$ infective centres. Plates containing $40 \mathrm{ml}$. of ' $\lambda$ agar' were used, after drying with lids removed for $30 \mathrm{~min}$. at $37^{\circ}$. The plates were maintained closed at $37^{\circ}$ until the overlayers containing the infective centres were ready to pour. The overlayers were prepared by mixing the unknown sample containing infective centres with about $10^{8}$ exponentially growing indicator organisms ( $6600 \mathrm{Sr}^{\mathrm{r}} \mathrm{T}_{6}{ }^{\mathrm{r}} \lambda^{\mathrm{s}} \mathrm{F}^{-}$) and $3 \mathrm{ml}$. of top agar. Where necessary $200 \mu \mathrm{g}$. streptomycin $/ \mathrm{ml}$. was added to both the $\lambda$ agar and the top agar.

Population densities of bacterial cultures were determined with the aid of a Petroff-Hausser counting chamber.

Testing for $\boldsymbol{F}$ infection. Separated areas, about 7-8 $\mathrm{mm}$. diameter on a nutrient agar plate were spread with re-isolated clones, and reference $\mathrm{F}^{+}$and $\mathrm{F}^{-}$clones. Following incubation of these masterplates at $37^{\circ}$ for $3 \mathrm{hr}$. the growth was replica plated (Lederberg \& Lederberg, 1952) on to a lawn of a suitable auxotrophic $F^{-}$ strain prepared on minimal agar supplemented with $\mathrm{D}$-glucose (2 g./l.) and thiamin $\left(5 \mu \mathrm{g} . / \mathrm{ml}\right.$.). These plates were incubated at $37^{\circ}$ for $24-36 \mathrm{hr}$., when areas corresponding to $\mathrm{F}^{+}$strains on the masterplates show about 20 recombinant colonies.

The same clones were scored for $\lambda$ lysogeny by replicating growth from a second set of masterplates (carrying reference lysogenic and non-lysogenic clones) on $\lambda$ agar seeded with indicator bacteria. The plates were incubated for $3 \mathrm{hr}$. at $37^{\circ}$ 
and then irradiated by u.v. for $30 \mathrm{sec}$. at $50 \mathrm{~cm}$. from a Honovia, $15 \mathrm{~W}$. lowpressure u.v. lamp. After irradiation, the plates were incubated for a further $18 \mathrm{hr}$. in the dark at $37^{\circ}$. With this technique lysogenic clones were surrounded by a narrow band of lysis of the indicator strain.

For the conjugation experiments all cultures were grown for $105 \mathrm{~min}$. in broth at $37^{\circ}$ after $1 / 11$ dilution of an overnight culture. Matings were also performed in broth.

\section{RESULTS}

Zygotic induction occurs under certain conditions when an inducible prophage is injected from a lysogenic $\mathbf{H f r}$ cell into a sensitive $\mathbf{F}^{-}$cell. This selects against the recovery of Hfr genetic markers closely linked to the site of the prophage, because of the greater probability of their joint injection. Thus the recovery of recombinants carrying these markers is reduced with increasing frequency of zygotic induction. A useful marker closely linked to the site of the $\lambda$ prophage is one which controls the fermentation of galactose, namely gal $_{\mathrm{b}}$.

\section{Cytoplasmic transfer by $\mathrm{F}^{+}$cells}

To prevent direct infection of recipient organisms by free $\lambda$ phage, which is present in cultures of lysogenic bacteria, a recipient which does not adsorb the phage was used, namely $\mathbf{P} 678 \lambda \mathbf{r}^{-}$. Parallel mixtures were made from a culture of this strain with the three donor strains, $\mathrm{C} 600 \mathrm{~S}^{8} \mathrm{~F}^{+}$(non-lysogenic); $\mathrm{C} 600 \mathrm{~S}^{\mathrm{s}}\left(\lambda^{+}\right)$;

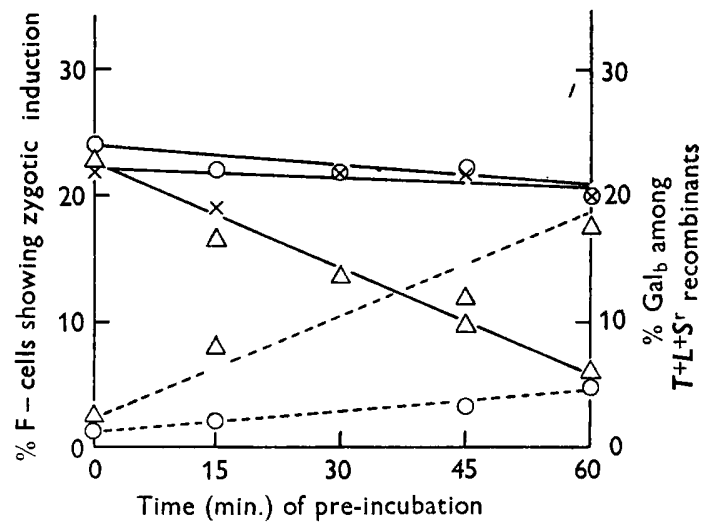

Fig. 1. Three cultures of Escherichia coli $\mathrm{K}-12$ strain $\mathrm{P} 678 \mathrm{~F}^{-}$were prepared in broth at $37^{\circ}$ containing about $2 \times 10^{8}$ organisms $/ \mathrm{ml}$. To one was added about $2 \times 10^{8} \mathrm{C}_{600} \mathrm{~S}^{\mathrm{s}} \mathrm{F}^{+}$ (non-lysogenic), to the second about $2 \times 10^{8} \mathrm{C600}\left(\lambda^{+}\right) \mathrm{S}^{8} \mathrm{~F}^{+}$(lysogenic) and to the third about $2 \times 10^{8} \mathrm{Hfr} \mathbf{P} 4 \mathbf{X}\left(\lambda^{+}\right) \mathrm{S}^{\mathrm{s}}$ (lysogenic). At times indicated on the abscissa, samples were removed from the cultures, agitated vigorously to separate pairs, and added to about $2 \times 10^{8}$

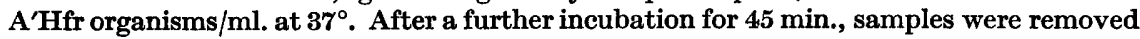
and appropriate dilutions plated on minimal agar supplemented with glucose thiamin and streptomycin to assay for $\boldsymbol{T}^{+} \boldsymbol{L}^{+} \boldsymbol{S}^{\mathrm{r}}$ recombinants formed. Parallel samples were plated with indicator strain, $\mathrm{C} 600 \mathrm{~S}^{\mathrm{r}} \mathrm{T}_{6}{ }_{6} \lambda^{\mathrm{s} F}-$ on agar supplemented with streptomycin to assay for $\lambda$ infectious centres. The $T^{+} L^{+} S^{r}$ recombinants were analysed for ability to ferment galactose (inheritance of $\mathrm{gal}_{\mathrm{b}}{ }^{+}$from $\mathbf{A}^{\prime} \mathbf{H f r}$ ) and for lysogeny. $O=$ pre-incubation with $\mathbf{C 6 0 0}$ $\mathrm{S}^{\mathrm{s}} \mathrm{F}^{+} ; \quad \times=$ pre-incubation with $\mathrm{HfrP4X}\left(\lambda^{+}\right) \mathrm{S}^{\mathrm{s}} ; \Delta=$ pre-incubation with $\mathbf{C 6 0 0}$ $\left(\lambda^{+}\right) \mathbf{F}^{+} ;---$, gal $_{\mathrm{b}}+$ inheritance; $\longrightarrow$, zygotic induction $\left(\lambda\right.$ plaques as $\% \mathbf{P 6 7 8} \mathbf{F}^{-}$ bacteria plated.). 
and Hfr P4X $\mathrm{XS}^{\mathrm{s}}\left(\lambda^{+}\right)$. This particular Hfr strain carries $\lambda$ prophage near to the distal extremity of the chromosome and it is not therefore transferred to $\mathrm{F}^{-}$cells during the time of the experiment. At intervals after preparing the three mixtures, samples were removed from each and added to separate samples of strain $\mathbf{A}^{\prime} \mathbf{H f r}$ to give about equal numbers of $\mathbf{A}^{\prime} \mathbf{H f r}$ and $\mathbf{F}^{-}$organisms. These mixtures were left for a further $45 \mathrm{~min}$. at $37^{\circ}$ to permit transfer of the $\lambda$ prophage, effected by $\mathbf{A}^{\prime} \mathrm{Hfr} 28 \mathrm{~min}$. after making contact with an $\mathbf{F}^{-}$organism. When the latter is not lysogenic for $\lambda$, there is a very high probability that zygotic induction will occur. This frequency of zygotic induction was determined by plating suitable dilutions

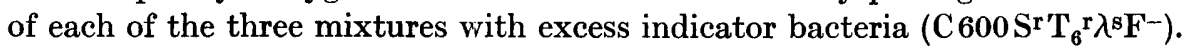

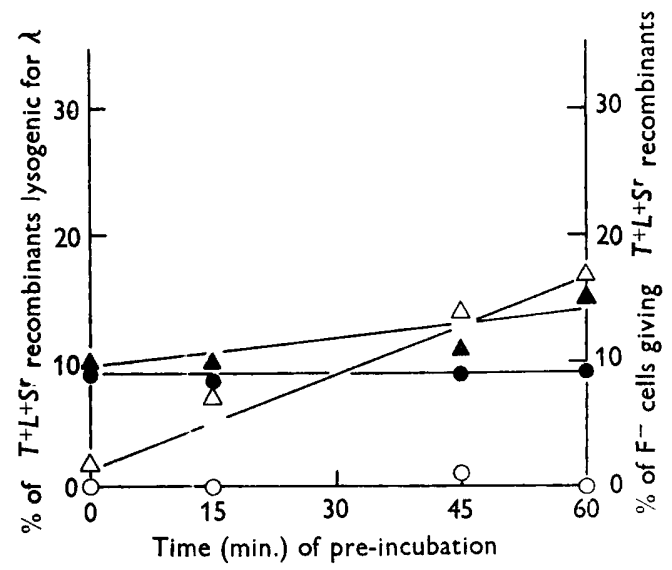

Fig. 2. For experimental conditions see legend to Fig. 1. = pre-incubation with C600 $\mathrm{S}^{\mathrm{s}} \mathbf{F}^{+}, \%$ of $\mathbf{F}-$ cells giving $\boldsymbol{T}^{+} \boldsymbol{L}^{+} \boldsymbol{S}^{\mathbf{r}}$ recombinants; $\boldsymbol{\Delta}=$ pre-incubation with C600 $\mathrm{S}^{\mathrm{a}}\left(\lambda^{+}\right) \mathbf{F}^{+}, \%$ of $\mathbf{F}-$ cells giving $\boldsymbol{T}^{+} \boldsymbol{L}^{+} \boldsymbol{S}^{\mathbf{r}}$ recombinants; $\bigcirc=$ pre-incubation

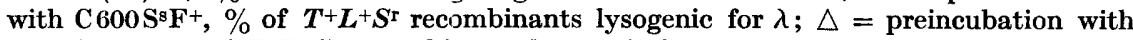
$\operatorname{C600S}^{\mathrm{s}}\left(\lambda^{+}\right), \%$ of $\boldsymbol{T}^{+} \boldsymbol{L}^{+} \boldsymbol{S}^{\mathrm{r}}$ recombinants lysogenic for $\lambda$.

From Fig. 1 it can be seen that where pre-incubation was with a lysogenic $\mathbf{F}^{+}$ strain, the frequency of zygotic induction was decreased from $23 \%$ of $\mathrm{F}^{-}$cells to $6 \%$ after $60 \mathrm{~min}$. pre-incubation. In the case of pre-incubation with a non-lysogenic $\mathrm{F}^{+}$or lysogenic $\mathrm{Hfr}$ the frequency of zygotic induction was only decreased by $3-5 \%$ over the same period.

Besides assaying for zygotic induction, parallel samples of the three mixtures were plated on minimal agar supplemented with streptomycin and thiamin to select for $T^{+} L^{+} S^{\text {r }}$ recombinants. These were subsequently tested for the inheritance of $\mathrm{gal}_{\mathrm{b}}{ }^{+}$and $\lambda$ prophage from $\mathrm{A}^{\prime} \mathbf{H f r}$. The latter part of the analysis cannot be applied to samples involving pre-incubation with $\mathbf{H f r} \mathbf{P} 4 \mathbf{X}$, since this gives rise to large numbers of recombinants which cannot be distinguished from those due to $\mathbf{A}^{\prime} \mathbf{H} f$. Figure 1 shows that the recovery of gal $_{\mathrm{b}}+$ increased from 2 to $18 \%$ following preincubation for $60 \mathrm{~min}$. with a lysogenic $\mathrm{F}^{+}$; pre-incubation with a non-lysogenic $\mathrm{F}^{+}$for the same period produced a very small effect. Pre-incubation of lysogenic $\mathrm{F}^{+}$cells with non-lysogenic $\mathrm{F}^{-}$cells resulted in an increase, from 10 to $15 \%$, of the F - cells which yielded $T^{+} L^{+} S^{\text {r }}$ recombinants (Fig. 2). Over the same period, the proportion of these recombinants which were lysogenic for $\lambda$ increased from 
3 to $17 \%$ (Fig. 2). Pre-incubation with a non-lysogenic $\mathbf{F}^{+}$showed no effect. The decrease in the frequency of zygotic induction can be explained in two ways. Either the pre-incubation with a lysogenic $\mathbf{F}^{+}$in some way prevents the $\mathbf{A}^{\prime} \mathbf{H}$ fr from injecting its genetic material together with the prophage, or the pre-incubation allows passage of the repressor of vegetative growth of $\lambda$. Recovery of the $g a l_{\mathrm{b}}$ markers (Fig. 1) amongst the $\boldsymbol{T}^{+} \boldsymbol{L}^{+} \boldsymbol{S}^{\mathrm{r}}$ recombinants isolated, following pre-incubation with a lysogenic $\mathbf{F}^{+}$increases, thus ruling out the first possibility. Thus one concludes that an $\mathbf{F}^{+}$lysogenic cell transfers $\lambda$ immunity when it conjugates with an $\mathrm{F}^{-}$cell whereas an $\mathrm{Hfr}$ lysogenic cell does not do so to a detectable extent. The fact that zygotic induction is observed in $\mathrm{Hfr} \times \mathrm{F}^{-}$crosses, in itself indicates an absence of transfer of $\lambda$ immunity.

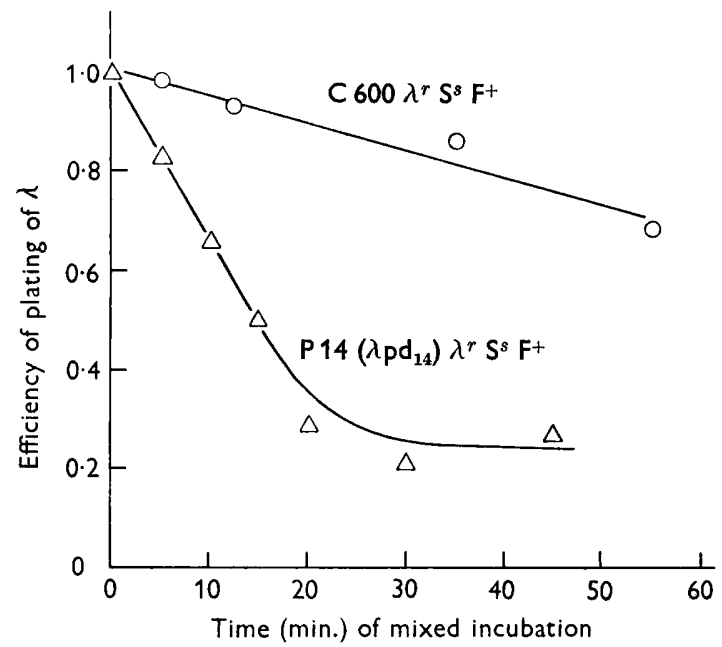

Fig. 3. Two mixed cultures of Escherichia coli $\mathrm{K}-12$ in broth at $37^{\circ}$ were prepared containing about $2 \times 10^{8}$ organisms $\mathrm{C} 600 \mathrm{~S}^{\mathrm{r}} \mathrm{T}_{6}{ }^{\mathrm{r}} \lambda^{\mathrm{s}} \mathrm{F}^{-} / \mathrm{ml}$. and about $2 \times 10^{8}$ organisms of

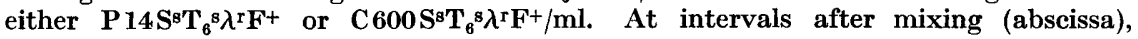
samples were removed to a mixture of coliphage $\mathrm{T} 6$ and wild-type $\lambda$ phage, such that the input multiplicity of $\lambda$ for the $F^{-}$strain was about $0 \cdot 5$. These mixtures were agitated vigorously and then incubated for $15 \mathrm{~min}$. at $37^{\circ}$. Suitable dilutions were plated, with excess $\mathrm{C} 600 \mathrm{~S}^{\mathrm{r}} \mathrm{T}_{6}{ }^{\mathrm{r}} \lambda^{\mathrm{B}} \mathrm{F}^{-}$organisms as indicator, on $\lambda$ agar supplemented with streptomycin, to assay for $\lambda$ infectious centres. The efficiency of plating (ordinate) is given by (no. of infectious centres at time $T /$ unit sample) $\div$ (no. of infectious centres at time o/unit sample).

\section{Transfer of repressor with challenge by free $\lambda$ particles}

The immunity of lysogenic bacteria to lysis by superinfecting phage has been attributed to the cytoplasmic repressor (Jacob \& Campbell, 1959). Accordingly, the ability of passively immunized cells (i.e. cells immunized by conjugal transfer of the repressor material) to suppress the plaque-forming ability of the wild-type $\lambda$ particles was determined. Broth cultures of normal lysogenic cells in the middle of the exponential growth phase contain about $10^{6}$ infective $\lambda$ particles $/ \mathrm{ml}$. Obviously such a culture cannot be used to transfer repressor substance to $\lambda$ sensitive cells. For this reason an $F+$ strain carrying a defective prophage $\left(\lambda \operatorname{pd}_{14}{ }^{+}\right)$ was used as the immunizing strain. Broth cultures of this organism have only 
about 10 p.f.p./ml. The parent cultures were mixed, and at intervals samples removed to a mixture of coliphages $\mathrm{T} 6$ and $\lambda$. The input multiplicities of the two phages were 100 and $0 \cdot 5$, respectively, the coliphage $\mathbf{T} 6$ being used to kill the donor strain and the $\lambda$ phage to determine the immunity of the recipient organisms.

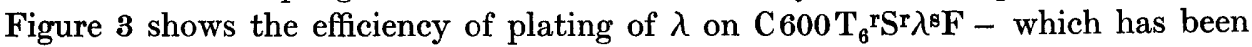
incubated for varying periods of time (abscissa), either with P14 $\left(\lambda \mathrm{d}_{14}{ }^{+}\right)_{6}{ }_{6}{ }^{s}{ }^{s} \lambda r F^{+}$ or $\mathrm{C}_{600} \mathrm{~T}_{6}{ }^{\mathrm{s}} \mathrm{S}^{\mathrm{s}} \lambda^{\mathrm{r}} \mathrm{F}^{+}$(i.e. a lysogenic or non-lysogenic $\mathrm{F}^{+}$). Pre-incubation for $45 \mathrm{~min}$. with the lysogenic $\mathrm{F}^{+}$resulted in protection of about $75 \%$ of the recipient cells, whereas pre-incubation with a non-lysogenic $\mathbf{F}^{+}$strain for the same period protected only about $25 \%$. The protection afforded by the latter may have been due to steric blocking of $\lambda$ receptor sites on the surface of the $\mathbf{F}^{-}$cells by attached $\mathrm{F}^{+}$bacteria. It was noted during the course of these experiments that there was a background of indistinct phage plaques whenever coliphage $\mathrm{T} 6$ was added at high multiplicity (about 100 particles $/ \mathrm{F}^{+}$organism) to an $\mathrm{F}^{+} \mathbf{T}_{6}{ }^{\mathrm{s}} \times \mathrm{F}^{-} \mathbf{T}_{6}{ }^{\mathbf{r}}$ mixture. Similar samples of $\mathrm{T} 6$, when plated on $\mathrm{F}^{-}$cells, show very few plaques, presumably formed by host range mutants. 'The plaques due to $\lambda$ which had to be read against the above-mentioned background could be distinguished by their typical morphology.

\title{
Table 2. The independent transfer of $F$ factor and immunity to $\lambda$ multiplication
}

\begin{abstract}
Parallel mixtures of the two Escherichia coli K-12 donor strains $P 14\left(\lambda d_{14}{ }^{+}\right) \lambda^{r} F^{+}$

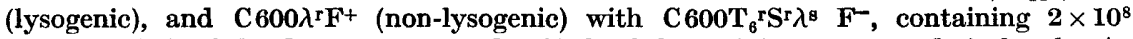
organisms $/ \mathrm{ml}$. of the donor parent and $10^{8} / \mathrm{ml}$. of the recipient were made in broth. At the times shown samples were removed to a mixture of coliphage $T 6$ (multiplicity of 100) and $\lambda$ (input multiplicity of 0.5) and incubated at $37^{\circ}$ for 15 min. Appropriate dilutions were plated on nutrient agar containing $200 \mu \mathrm{g}$. streptomycin $/ \mathrm{ml}$. to re-isolate the recipient strain. These were examined for lysogeny, which is taken as an indication of a temporarily immune cell at the time of infection with $\lambda$, and for $F$ character. Percentages of re-isolated $\mathrm{F}^{-}$clones having acquired $F$ and/or lysogeny are given.
\end{abstract}

Time (min.) after mixing donor and recipient organisms

\begin{tabular}{|c|c|c|c|c|}
\hline \multirow[t]{2}{*}{$\begin{array}{l}\min .) \text { after } \\
\text { donor and } \\
\text { t organisms }\end{array}$} & \multicolumn{4}{|c|}{$\begin{array}{c}\text { Donor strain P } 14\left(\lambda \mathrm{d}_{14}+\right) \lambda^{\mathrm{r}} \mathrm{F}^{+} \\
\text {Characters of re-isolated } \\
\text { recipient clones }(\%)\end{array}$} \\
\hline & $\mathbf{F}+\lambda-$ & $\mathbf{F}^{-} \lambda^{+}$ & $\mathbf{F}^{+} \lambda^{+}$ & $\mathbf{F}^{-} \lambda-$ \\
\hline 0 & 4 & J. & 0 & 95 \\
\hline 10 & 14 & 16 & 2 & 68 \\
\hline 20 & 28 & 18 & 1 & 53 \\
\hline 30 & 31 & 20 & 6 & 43 \\
\hline 40 & 30 & 25 & 7 & 38 \\
\hline
\end{tabular}

\section{Donor strain P14 $\left(\lambda \mathrm{d}_{14}{ }^{+}\right) \lambda^{\mathrm{r}} \mathrm{F}^{+}$ Characters of re-isolated recipient clones (\%)}

\begin{tabular}{|c|c|c|c|}
\hline \multicolumn{4}{|c|}{$\begin{array}{c}\text { Donor strain } \mathrm{C} 600 \lambda \mathrm{r} \mathrm{F}^{+} \\
\text {Characters of re-isolated } \\
\text { recipient clones }(\%)\end{array}$} \\
\hline $\mathbf{F}^{+}+\lambda-$ & $\mathbf{F}^{-} \lambda^{+}$ & $\mathbf{F}^{+} \lambda^{+}$ & $F^{-} \lambda^{-}$ \\
\hline 3 & 0 & 0 & 97 \\
\hline 10 & 3 & 1 & 86 \\
\hline 23 & 6 & 1 & 70 \\
\hline 38 & 9 & 0 & 53 \\
\hline 42 & 4 & 1 & 53 \\
\hline
\end{tabular}

\section{Transfer of the fertility factor $\mathrm{F}$ and of repressor as distinct events}

The ability of $\mathrm{F}^{+}$cells to convert $\mathrm{F}^{-}$cells, by contact, to $\mathrm{F}^{+}$has been established for a considerable time (Cavalli, Lederberg \& Lederberg, 1953; Hayes, 1953). The high efficiency with which $F$ is transferred suggested the possibility of its simultaneous transfer with the repressor substance. To test this, parallel mixtures of P14 $\left(\lambda \mathrm{d}_{14}{ }^{+}\right) \mathrm{T}_{6}{ }^{\mathrm{s}} \mathrm{S}^{\mathrm{s}} \lambda \mathrm{r} \mathrm{F}^{+}$(lysogenic) cells or $\mathrm{C}_{600} \mathrm{~T}_{6}{ }^{\mathrm{B}} \mathrm{S}^{\mathrm{s}} \lambda^{\mathrm{r}} \mathrm{F}^{+}$(non-lysogenic) cells with $\mathrm{C}_{600} \mathrm{~T}_{6}{ }_{6} \mathrm{~S}^{\mathrm{r}} \lambda^{\mathrm{s}} \mathrm{F}$ - cells were prepared. At intervals, samples were treated with coliphage $\mathbf{T} 6$ (to destroy the donor cells) and $\lambda$ added at an input multiplicity of 0.5 . Samples of suitable dilutions were plated on streptomycin agar to re-isolate the recipient strain. These were subsequently tested for $F$ character and lysogeny (as an indication of immunity transfer). The results shown in Table 2 suggest that 
fertility factor $F$ and $\lambda$ immunity are transferred independently, the recovery of $7 \% \mathrm{~F}^{+}\left(\lambda^{+}\right)$clones at $\mathbf{4 0} \mathrm{min}$. being close to the expected value, $7.5 \%$ (calculated as the product of independently acquired factors). The results are complicated, however, by the fact that unmated $\mathrm{F}^{-}$cells will either be destroyed by lytic infection of $\lambda$ or be scored as $\mathbf{F}^{-} \lambda-$. Similarly, a proportion of those cells which at the time of infection by $\lambda$ have acquired $F$ but not $\lambda$ immunity, will also be lysed.

\section{DISCUSSION}

The immunity of lysogenic bacteria to related superinfecting bacteriophages has been equated with regulation of enzyme synthesis (Jacob, Perrin Sanchez \& Monod, 1960). The demonstration that a cytoplasmic factor, i.e. non-chromosomal, can be transferred from $\mathrm{F}^{+}$cells to $\mathrm{F}^{-}$cells to produce immunity of the $\mathrm{F}^{-}$cell verifies the existence of the repressor substance. Further evidence (Fisher, to be published) suggests that the immunity is of a temporary nature. Although in this paper the repressor has been used as a tool to demonstrate cytoplasmic transfer it is obvious that new experimental vistas, in the direction of regulation of protein synthesis, are opened up by the ability to isolate the repressor from its site of synthesis. Experiments have been started with this end in view. The fact that there is at least partial mutual exclusion of cytoplasmic and chromosomal transfer in the Escherichia coli K-12 conjugation system is of interest from the point of view of the mechanism of transfer. Whether or not the alternatives, i.e. cytoplasmic or chromosomal transfer in $\mathbf{F}^{+} \times \mathbf{F}^{-}$and $\mathbf{H f r} \times \mathbf{F}^{-}$crosses, respectively, have a common mechanism or if each has a separate mechanism is not known. The transfer of genetic material associated with the fertility factor $F^{\prime}$, reported by Adelberg \& Burns (1960), may argue in favour of a common mechanism for transfer. This would lead to the suggestion that the mere possession of $F$ by a cell enables it to perform the preliminary steps in its role as donor and the exclusion of either cytoplasmic or chromosomal transfer would be decided by other factors. The proposed circular chromosome in $E$. coli K-12 (Jacob \& Wollman, 1958) may be a restraint on transfer of chromosomal material in $\mathbf{F}^{+} \times \mathbf{F}^{-}$crosses. The evidence for its linear nature in Hfr strains allows one to suggest that in $\mathbf{H f r} \times \mathbf{F}^{-}$crosses, the chromosome from the donor, once it has begun to enter the intercellular bridge, effectively blocks the tube and prevents cytoplasmic transfer. There exists, of course, the possibility of cytoplasmic transfer in $\mathrm{Hfr} \times \mathrm{F}^{-}$crosses occurring before chromosome movement starts. This might explain the early transfer of $F^{\prime}$ factors in $\mathrm{Hfr} \times \mathrm{F}^{-}$crosses.

The transfer of cytoplasm in $\mathrm{F}^{+} \times \mathrm{F}^{-}$crosses may explain the observations of Borek \& Ryan (1958) on cross-induction where conjugation of a previously u.v.irradiated non-lysogenic $\mathbf{F}^{+}$culture with a lysogenic $\mathbf{F}^{-}$culture led to the induction of the prophage carried by the $\mathrm{F}^{-}$cell. In addition, Borek \& Ryan (1960) showed that there was cross-induction to a lesser extent in $\mathrm{Hfr} \times \mathrm{F}^{-}$crosses. If this involves cytoplasmic transfer it may be confined to $\mathrm{Hfr} / \mathrm{F}^{-}$pairs which have not initiated chromosome movement.

Work on the transfer of colicin factors (Fredericq \& Betz-Bareau, 1953; Alfoldi, Jacob \& Wollman, 1957; Alfoldi, Jacob, Wollman \& Mazé, 1958) shows that $\mathrm{F}^{+}$ strains transmit colicin factor $E 1$ to about $70 \%$ of $\mathrm{F}^{-}$cells in mixed cultures. The 
degree of transfer of colicin $\boldsymbol{E} \mathbf{1}$ effected by $\mathbf{H f r}$ strains to $\mathrm{F}^{-}$cells, however, varies from 1 to $80 \%$ (Alfoldi et al. 1958) according to the particular Hfr strain used. Alfoldi et al. (1958) suggested that colicinogenic factors can exist as cytoplasmic or chromosomal entities. If this be true, the low rate of transfer of colicin factor $E 1$ effected by certain Hfr strain, might be due to lack of cytoplasmic transfer in $\mathbf{H f r} \times \mathbf{F}^{-}$crosses. In connexion with $\mathbf{F}^{+} \times \mathbf{F}^{-}$crosses, Drs $\mathbf{R}$. C. Clowes and D. Hild (personal communication) have concluded from preliminary experiments that there is independent transfer of three entities namely the $E 1$ colicinogenic factor, $F$ factor and $\lambda$ immunity, from $F^{+}$to $F^{-}$cells. In the case of colicinogeny for $E 1$, the transfer appears to be only from $\mathrm{F}^{+}$to $\mathrm{F}^{-}$cells, confirming the observations of Alfoldi et al. (1957).

Jacob, Schaeffer \& Wollman (1960) have stated that the $\boldsymbol{F}$ factor of Escherichia coli K-12 cannot exist in an autonomous state in Hfr cells. However, the fact that there is little or no cytoplasmic transmission by Hfr cells precludes any direct test of this. Consequently, without experimental test, it cannot be held that chromosomal attachment of $\boldsymbol{F}$ in Hfr cells is the result of, or causes the establishment of an immunity mechanism for $F$, comparable to that established for $\lambda$ phage. Recent experiments by Scaife \& Gross (1962) have indicated that an $F^{\prime}$ lac factor introduced into an $\mathrm{Hfr}$ cell by infection cannot multiply autonomously. This observation supports the suggestion of Jacob, Schaeffer \& Wollman (1960) regarding the establishment of an immunity mechanism for $F$.

My thanks are due to friends and colleagues who have made constructive suggestions during this work and preparation of the paper.

\section{REFERENCES}

Adelburg, E. A. \& Burns, S. N. (1960). Genetic variation in the sex factor of Escherichia coli. J. Bact. 79, 321.

Alfoldi, L., JACOB, F. \& Wollman, E. L. (1957). Zygose létale dans des croisements entre souches colicinogènes et non colicinogènes d'Escherichia coli. C.R. Acad. Sci., Paris, 244, 2974.

Alfoldi, L., JACob, F., Wollman, E. L. \& Mazé, R. (1958). Sur le déterminisme génétique de la colicinogénie. C.R. Acad. Sci., Paris, 246, 3531.

Bertani, G. (1956). The role of phage in bacterial genetics. Brookhaven symp. Biol. 8, 50.

Bertani, G. \& Six, E. (1958). Inheritance of prophage P2 in bacterial crosses. Virology, 6, 357 .

Borek, E. \& Ryan, A. (1958). The transfer of irradiation elicited induction in a lysogenic organism. Proc. nat. Acad. Sci., Wash. 44, 374.

Bonex, E. \& Ryan, A. (1960). The transfer of a biologically active irradiation product from cell to cell. Biochim. Biophys. Acta, 41, 57.

Cavali, L. L., Lederberg, J. \& Lederberg, E. M. (1953). An infective factor controlling sex compatibility in Bacterium coli. J. gen. Microbiol. 8, 89.

FredericQ, P. \& Betz-Bareau, M. (1953). Transfert génétique de la propriété colicinogénie en rapport avec la polarité F des parents. C.R. Soc. Biol., Paris, 147, 2043.

HAYES, W. (1953). Observations on a transmissible agent determining sexual differentiation in Bacterium coli. J. gen. Microbiol. 8, 72.

$\mathrm{J}_{\text {ACoB, }}$ F. \& CAmpbell, A. (1959). Sur le système de répression assurant l'immunité chez les bactéries lysogènes. C.R. Acad. Sci., Paris, 248, 3219.

$\mathrm{J}_{\mathrm{ACOB}, \mathrm{F}}$ \& MoNOD, J. (1961). Genetic regulatory mechanisms in the synthesis of proteins. J. mol. Biol. 3, 318. 
$\mathrm{J}_{\mathrm{ACOB}}, \mathbf{F}$. \& Wollman, E. L. (1954). Induction spontanée du dévelopment du bactériophage $\lambda$ au cours de la recombinaison génétique chez E. coli K-12. C.R. Acad. Sci., Paris, 239, 317.

$\mathrm{J}_{\mathrm{ACOB}}, \mathrm{F}$. \& Wollman, E. L. (1958). Genetic and physical determinations of chromosomal segments in Escherichia coli. Symp. Soc. exp. Biol. 12, 75.

Jacob, F., Schaeffer, P. \& Wollman, E. L. (1960). Episomic elements in bacteria. Symp. Soc. gen. Microbiol. 10, 67.

Jacob, F., Perrin, D., Sanchez, C. \& Monod, J. (1960). L'opéron: Groupe de gènes à l'expression coordonnée par un operateur. C.R. Acad. Sci., Paris, 250, 1727.

LeDerberg, J. \& Lederberg, E. M. (1952). Replica plating and indirect selection of bacterial mutants. J. Bact. 63, 399.

Pardee, A. B., Jacob, F. \& Monod, J. (1959). The genetic control and cytoplasmic expression of 'inducibility' in the synthesis of $\beta$-galactosidase by E. coli. J. mol. Biol. 1, 165.

Scarfe, J. \& Gross, J. D. (1962). Inhibition of multiplication of an F-lac factor in Hfr cells of Escherichia coli K.12. Biochem. biophys. res. Comm. 7, 403.

TAtum, E. L. \& LeDerberg, J. (1947). Gene recombination in the bacterium Escherichia coli. J. Bact. 53, 673. 
